mechanisms. Sleep deprivation, usually associated with stress and fatigue, is a frequent trigger in patients with temporal lobe epilepsy whereas sleep predisposes to extratemporal and especially frontal lobe nocturnal epilepsy. Cryptogenic generalized epilepsies are less susceptible to the effects of sleep deprivation.

Numerous reflex epilepsy syndromes are described in children. These include epilepsy induced by "Soroban," a Japanese calculator; reading epilepsy, graphogenic, arithmetic, cards and game playing, piano, Nintendo and Rubik's cube epilepsy. Both mental activity under psychological tension and movements of fingers are involved in the induction of seizures in susceptible patients. (See Progress in Pediatric Neurology II, PNB Publ, 1994;pp60-61).

\title{
CHILDHOOD EPILEPSY WITH OCCIPITAL PAROXYSMS:VARIANTS
}

The recent ILAE classification of "childhood epilepsy with occipital paroxysms. (CEOP)" into two distinct syndromes was tested at the Schneider Children's Medical Center, Tel Aviv University, and Rappaport Medical School, Haifa, Israel. Of patients with partial-onset seizures and interictal occipital spikes referred to the pediatric seizure unit between Jan 1975 and May 1997, 134 met criteria for CEOP. Three clinical groups were defined: Group 1 (visual) with ictal visual symptoms (24 patients (18\%)); Group 2 (adversive) with tonic eye deviation (72 patients (54\%)); Group 3 (nonvisual, nonadversive) with various seizure patterns (38 patients (28\%). Two syndromes were identified: 1) Gastaut type, late onset (median age 8 years), with brief and frequent diurnal seizures, included the Group 1 visual type; and 2) the Panayiotopoulos type, early onset (median age 5 years), with ictal eye deviation and ictal vomiting, infrequent nocturnal seizures, included the patients in Group 2 adversive type. The patients in Group 3 did not satisfy criteria for either syndrome. (Kivity S, Ephraim T, Weitz R, Tamir A. Childhood epilepsy with occipital paroxysms: clinical variants in 134 patients. Epilepsia Dec 2000;41:1522-1533). (Reprints: Dr S Kivity, Pediatric Epilepsy Unit, Schneider Children's Medical Center of Israel, Petah Tiqva 49202, Israel).

COMMENT. The authors conclude that Panayiotopoulos syndrome is the most common variant of CEOP, and the symptoms are sufficiently delineated to justify classification separate from the Gastaut type CEOP and, also, from BECT, another idiopathic localization-related epilepsy. For all these idiopathic epilepsy syndromes, the prognosis is generally good.

Occipital epileptiform discharges in the EEG can also be associated with symptomatic epilepsies that carry a poor prognosis. Background slowing in the EEG is predictive of persistent seizures and developmental delay (Libenson $\mathrm{MH}$ et al, 1999; see Ped Neur Briefs Aug 1999;13:63).

\section{EXCESSIVE BRUISING AND THE KETOGENIC DIET}

Changes in platelet function and excessive bruising were investigated by chart review and prospective screening in 51 patients treated with the ketogenic diet for epilepsy at RUSH-Presbyterian-St Luke's Medical Center, Chicago, IL. A significant increase in bruising or other minor bleeding was reported and/or observed in $16(31 \%)$ patients. The complication was more frequent in younger patients but was independent of sex and number of concurrent anticonvulsants (AED). The average age of patients with bleeding was 5 years compared to 8 years for patients without bleeding. The possibility of an interaction with a specific AED was suggested by a $25 \%$ use of lamotrigine in patients with bruises compared to $8 \%$ use in the nonbruising group (not significant $\mathrm{p}=.11$ ). Five of 6 patients tested had prolonged bleeding times and all had diminished response to platelet 
aggregating agents. One had a latent von Willebrand disease. The mechanism of the diet-induced bruising may be complex, involving interaction between the diet and individual platelet dysfunction. A possible bleeding tendency should be evaluated in patients on the ketogenic diet who are candidates for surgery or anticoagulant therapy. (Berry-Kravis E, Booth G, Taylor A, Valentino LA. Bruising and the ketogenic diet: evidence for diet-induced changes in platelet function. Ann Neurol January 2001;49:98-103). (Respond: Dr Berry-Kravis, RUSH-Presbyterian-St Luke's Medical Center, 1725 West Harrison Street, Suite 718, Chicago, IL 60612).

COMMENT. Despite the absence of serious bleeding in this series of patients treated with the ketogenic diet, a 30\% incidence of diet-induced bruising deserves further study and evaluation. A possible interaction with lamotrigine is suggested in some patients receiving concurrent drug and diet.

This is not the first observation of platelet dysfunction and anemia as a complication of the ketogenic diet. Complications in $10 \%$ of 52 children treated by Ballaban-Gil et al, 1998 (see Ped Neur Briefs August 1998;12:60) included thrombocytopenia and hemolytic anemia. Valproate interaction could not be excluded in 29 (56\%). The proportion of ketogenic/antiketogenic foods was $4: 1$ in this study but was not specified in the above Pres St Luke's study. This report of diet-induced bruising is another reason to endorse the Mayo Clinic method of slow initiation of the diet with lower ratios, in place of the Hopkins recommended ratio of $4: 1$. Using the Mayo Clinic method, I have not encountered this or other serious complication as reported with the Hopkins regimen (Ped Neur Briefs 1998;12:61).

A fat-overload syndrome with neurologic complications is reported in 2 children receiving fat emulsion therapy. Both patients died and autopsy showed cerebral intravascular lipid deposition and areas of necrosis and hemorrhage. (Schulz PE et al, 1994; Progress in Pediatric Neurology III, PNB Publ, 1997;p98). A rapid rise in triglyceride levels was invoked as a factor in this complication.

\section{FAMILIAL MESIAL TEMPORAL LOBE EPILEPSY}

Clinical, genetic, and MR characteristics of 68 patients with familial mesial temporal lobe epilepsy (MTLE) were analysed at the University of CampinasUNICAMP, Brazil. Hippocampal atrophy (HA) was identified by MRI in $48(57 \%)$ of 84 patients examined. HA was present in $46 \%$ of 13 patients with seizure remission, in $51 \%$ of 16 patients whose seizures were well controlled by AEDs, and in all 16 patients with refractory MTLE. HA was also found in some patients without MTLE: in $30 \%$ of 10 patients with febrile seizures alone, $60 \%$ of 10 with generalized tonicclonic epilepsy, and in 1 of 4 with a single partial seizure. Familial MTLE is a heterogeneous syndrome with a genetic component in etiology. (Kobayashi E, Lopes-Cendes I, Guerreiro CAM et al. Seizure outcome and hippocampal atrophy in familial mesial temporal lobe epilepsy. Neurology January (2 of 2) 2001;56:166172). (Reprints: Dr F Cendes, Departamento de Neurologia, Faculdade de Ciencias MedicasUNICAMP, Caixa Postal 6111, Cidade Universitaria Zeferino Vaz Campinas SP, Brazil, CEP 13083-970).

COMMENT. In this series of patients with familial mesial temporal lobe epilepsy, $57 \%$ had MRI evidence of mesial temporal sclerosis. Hippocampal atrophy is found not only in patients with refractory epilepsy but also in patients with a favorable outcome. Genetically determined mechanisms may have a role in hippocampal damage in familial cases of MTLE. In contrast to most patients with temporal lobe epilepsy, a history of febrile seizures is uncommon in patients with familial TLE. 